\title{
Massive underwater volcano erupts
}

\section{Event at Axial Seamount tests new deep-sea observing network.}

\section{Alexandra Witze}

01 May 2015

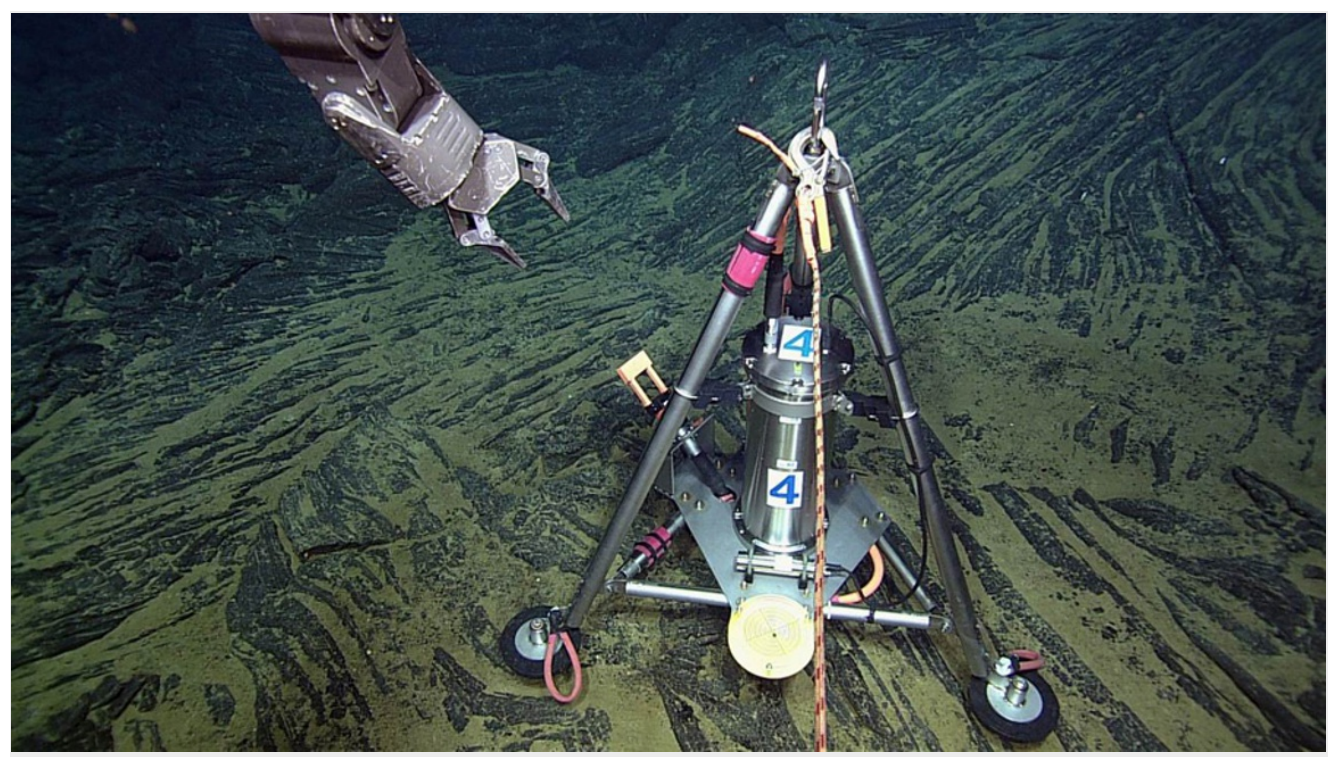

NSF/OONUniversity of Washington Instruments on the rim of the Axial Seamount measure the movement of the sea floor.

When the underwater Axial volcano erupted on 24 April, scientists were watching. Monitoring instruments on the sea floor off Oregon captured the action in real time, in an unprecedented look at a deep-sea eruption - the most common type of volcanic activity on Earth.

The event is the first major test for the US\$386-million Ocean Observatories Initiative (OOI). The programme, funded by the US National Science Foundation, is in the final stages of putting oceanographic instruments in dense networks in just a few portions of the ocean - including Axial Seamount.

"This is what l've been dreaming about for decades," says John Delaney, an oceanographer at the University of Washington in Seattle who spearheaded the drive to send data from Axial to shore along a sea floor cable. "This is a new era of exploration in the Earth sciences."

Not all of the information is making it to scientists in real time, however. Axial erupted before OOI project leaders could sort out how to publicly release all the data they are gathering. "If Mother Nature had waited for another three months this would be full-bore everything," says Delaney.

Axial, which last erupted in 2011, lies atop the Juan de Fuca Ridge, where hot magma wells up from deep inside the Earth and fills a reservoir beneath the volcano. When the pressure gets too great, the reservoir bursts like a balloon and squirts out magma. The sea floor drops down until the reservoir begins filling again.

The cycle is short and regular. Last year, researchers predicted that the volcano would erupt in 2015 because the sea floor around it was rising so quickly.

\section{Eyes open}

That seemed like perfect timing for the OOI. Last year, the project finished hooking the instruments on Axial — including seismometers, pressure and temperature sensors, and a mass spectrometer - into the umbilical cable running to the shore. If the volcano erupted, OOI scientists were ready to catch it in real time. 
On the evening of 23 April, seismometers around Axial recorded a huge spike in seismic activity. Small earthquakes began rattling at a rate of almost 8,000 per day, a nearly tenfold increase from before. William Wilcock, an oceanographer at the University of Washington, spotted the spike and alerted a group of scientists who, a day earlier, had just finished a planning workshop about what to do when Axial erupted.

"That's when the e-mails started flying," says William Chadwick, a geologist at Oregon State University and the US National Oceanic and Atmospheric Administration in Newport, Oregon.

Now, data from seven Axial seismometers are streaming to researchers via the website of the Incorporated Research Institutions for Seismology in Washington DC.

\section{Deep dive}

The earthquakes probably represent magma moving from deep within the reservoir out onto the sea floor, says Chadwick. Three other instruments, which measure pressure and ground deformation, show that the sea floor at Axial dropped by about 2.4 metres over the course of three days. That subsidence probably represents the top of the magma chamber sinking down as it drains.

The raw seismometer data are live, and next week the data from the ground-deformation instruments should be too. But there is a wealth of information from other instruments that is piling up on the OOI servers and not yet available to the wider scientific community.

"We're about $75 \%$ jazzed and $25 \%$ frustrated," Chadwick says. "We're poised to learn a lot more when we're able to look at all the data and get everybody involved and compare notes."

Even so, researchers won't know exactly what happened on the sea floor until they get out to Axial the old-fashioned way — aboard ships this summer.

Nature | doi:10.1038/nature.2015.17463 